\title{
PENGARUH KUALITAS LAYANAN, LOKASI DAN KELENGKAPAN PRODUK TERHADAP KEPUTUSAN PEMBELIAN APOTEK KENCANA MAS SIDOARJO
}

\author{
Inggal Citra Puspitadewi ${ }^{1}$, Moch. Munir Rachman 2 \\ Universitas PGRI AdiBuana Surabaya1,2 \\ inggalcitra03@gmail.com
}

\begin{abstract}
ABSTRAK
Dijelaskan bahwa penelitian ini menganalisa pengaruh Pengaruh kualitas layanan, lokasi serta kelengkapan produk Terhadap Keputusan Pembelian Apotek Kencana Mas Sidoarjo. Teknik pengambilan sampel menggunakan Non Probability sampling. Sampel 161 responden. Hasil menyimpulkan bahwa ada pengaruh Kualitas layanan terhadap Keputusan Pembelian memiliki thitung sebesar 2.189 nilai signifikan sebesar $.030<, 05$. Lokasi terhadap Keputusan Pembelian memiliki $t_{\text {hitung }}$ sebesar 3.107dengan nilai signifikan sebesar .002<,05. Kelengkapan produk terhadap Keputusan Pembelian memiliki thitung sebesar 4.104dengan nilai signifikan sebesar .000 $(.000<, 05)$.

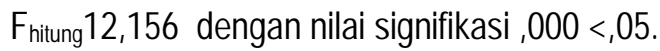

Kata kunci:Kualitas Layanan, Lokasi, Kelengkapan Produk dan Keputusan Pembelian.

\begin{abstract}
It was explained that this study analyzed the influence of the effect of service quality, location and product completeness on the Purchase Decision of Mas Sidoarjo Pharmacy. The sampling technique uses non probability sampling. Sample 161 respondents. The results concluded that there is an effect of service quality on Purchasing Decisions having a tcount of 2.189 a significant value of $.030<.05$. The location of the Purchasing Decision has a tcount of 3,107 with a significant value of .002 <.05. Completeness of the product against the Purchase Decision has a count of 4,104 with a significant value of $.000(.000<, 05)$. Fcount12,156 with significance value, $000<.05$.
\end{abstract}

Keyword:Service Quality, Location, Product Completeness and Purchasing Decisions. 


\section{PENDAHULUAN}

Dunia kesehatan kini menjadi bisnis paling ramai, banyaknya kasus wabah penyakit menjadi faktor utama makin banyaknya korban berjatuhan, Masyarakat kini berburu obat medis di Apotek. Salah satunya yakni Apotek Kencana Mas di pasar Krian dan berdiri cukup lama. Kehadiran apotek kencana mas dapat memberikan kemudahkan bagi para masyarakat disekitar apotek tersebut. Namun semakin hari semakin banyak bermunculan usaha-usaha yang sejenis yang letaknya juga berada di pasar krian. Hal ini membuat apotik Kencana Mas mengalami penurunan konsemen yang belanja atas pembelian obat-obatan.

Bagi bisnis apotek saat ini, kemampuan untuk memberikan kualitas layanan kepada konsumen menjadi tolak ukur keberhasilan dalam proses penjualan, konsumen akan merasa senang dan nyaman ketika melakukan pembelian obat-obatan di apotek kencana mas apabila semua layanan terfasilitasi dengan baik. Selain faktor layanan, faktor lain yang menjadi tolak ukur keputusan pembelian konsumen apotek kencana mas yakni lokasi, dengan lokasi apotek yang dekat dan mudah untuk di akses serta memiliki fasilitas tambahan seperti parkir kendaraan yang luas. Disisi lain apotek kencana mas sangat mengutamakan kelengkapan produk, Konsumen akan lebih tertarik apabila berkunjung ke apotek yang memiliki kelengkapan produk yang lebih banyak, hal ini dikarenakan konsumen menginginkan efisiensi waktu pada saat melakukan pembelian di apotek kencana mas.

Kini konsumen sangat ramai memburu jenis obat yang dapat membangkitkan imunitas, pantas saja hal ini terjadi karena adanya wabah penyakit menjadi pemicu ketakutan masyarakat, Apotek kencana mas bekerja ekstra keras dalam menyediakan stok obat-obatan agar konsumen dapat terlayani dengan baik.

\section{Rumusan Masalah \\ Dijelaskan dirumusan masalah sebagai berikut:}

1. Adakah pengaruh kualitas layanan terhadap keputusan pembelian Apotek Kencana Mas Sidoarjo?

2. Adakah pengaruh lokasi terhadap keputusan pembelian Apotek Kencana Mas Sidoarjo?

3. Adakah pengaruh kelengkapan produk terhadap keputusan pembelian Apotek Kencana Mas Sidoarjo?

4. Adakah pengaruh kualitas layanan, lokasi, dan kelengkapan produk secara simultan terhadap keputusan pembelian Apotek Kencana Mas Sidoarjo?

\section{Kerangka Konseptual}


Penulis mengilustrasikan kerangka konseptual seperti dibawah ini:

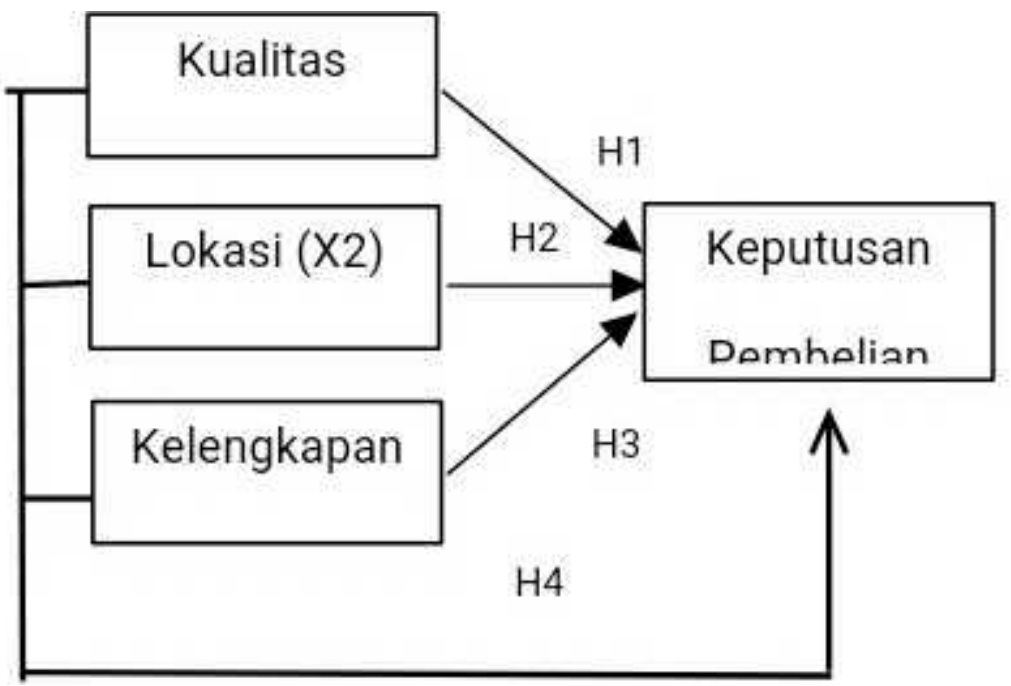

Gambar 1. Kerangka Konseptual

Tabel 1.

\section{METODE}

Dijelaskan pendekatan penelitian ini ialah kuantitatif. Teknik pengambilan sampel penelitian ini ialah non probability sampling. Penelitian ini akan menganalisa pengaruh variabel bebas yaitu Kualitas layanan , Lokasi, Kelengkapan produk, terhadap variabel terikat yaitu Keputusan Pembelian. Populasi dalam penelitian ini ialah konsumen yang berbelanja di apotek Kencana Mas Krian.

\section{Lokasi Penelitian}

Lokasi penelitian berada di apotek Kencana mas Krian jl. Basuku Rahman No.91A Krian Sidoarjo. Adapun waktu pelaksanaan penelitian selama dua minggu tanggal 6 sampai 19 januari 2020 pukul 08.00 sampai 12.00 siang.

HASIL
Hasil Uji Validitas

$\begin{array}{llll}\text { Kualitas Layanan } & & \\ \text { Ittem } & \text { r-hitung } & \text { Nilai kritis Keterangan } \\ \text { Ittem 1 } & , 928 & , 3 & \text { Vallid } \\ \text { Ittem 2 } & , 923 & , 3 & \text { Vallid } \\ \text { Ittem 3 } & , 941 & , 3 & \text { Vallid } \\ \text { Ittem 4 } & , 743 & , 3 & \text { Vallid } \\ \text { Ittem } & \text { r-hitung } & \text { Nilai kritis Keterangan } \\ \text { Ittem 1 } & , 635 & , 3 & \text { Vallid } \\ \text { Ittem 2 } & , 641 & , 3 & \text { Vallid } \\ \text { Ittem 3 } & , 734 & , 3 & \text { Vallid } \\ \text { Ittem 4 } & , 738 & , 3 & \text { Vallid } \\ \text { Ittem } & \text { r-hitung } & \text { Nilai kritis Keterangan } \\ \text { Ittem 1 } & , 788 & , 3 & \text { Vallid } \\ \text { Ittem 2 } & , 690 & , 3 & \text { Vallid } \\ \text { Ittem 3 } & , 697 & , 3 & \text { Vallid } \\ \text { Ittem 4 } & , 688 & , 3 & \text { Vallid } \\ \text { Ittem } & \text { r-hitung } & \text { Nilai kritis Keterangan } \\ \text { Ittem 1 } & , 640 & , 3 & \text { Vallid } \\ \text { Ittem 2 } & , 662 & , 3 & \text { Vallid } \\ \text { Ittem 3 } & , 759 & , 3 & \text { Vallid } \\ \text { Ittem 4 } & , 745 & , 3 & \text { Vallid } \\ \text { Ittem } & \text { r-hitung } & \text { Nilai kritis Keterangan } \\ \text { Ittem 1 } & , 753 & , 3 & \text { Vallid } \\ \text { Ittem 2 } & , 686 & , 3 & \text { Vallid } \\ \text { Ittem 3 } & , 714 & , 3 & \text { Vallid } \\ \text { Ittem 4 } & , 560 & , 3 & \text { Vallid } \\ \text { Lokasi } & & & \\ \text { Ittem } & \text { r-hitung } & \text { Nilai kritis Keterangan }\end{array}$




\section{Vol. 1 No. 1 Desember 2020}

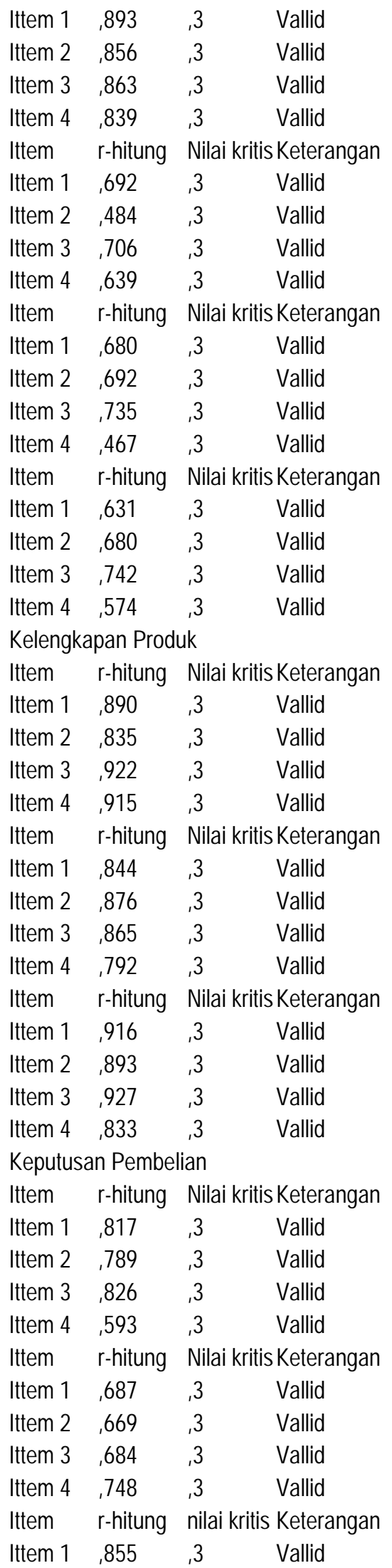

$\begin{array}{llll}\text { Ittem } 2 & , 766 & , 3 & \text { Vallid } \\ \text { Ittem } 3 & , 823 & , 3 & \text { Vallid } \\ \text { Ittem 4 } & , 676 & , 3 & \text { Vallid }\end{array}$

Dijelaskan validitas pada tabel 1 . nilai R-hitung $>0,3$ pada masing-masing variabel.

Tabel 2.

Hasil Uji Reliabilitas

\begin{tabular}{|c|c|c|c|}
\hline 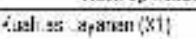 & Has: & $\mathrm{H}$ a kris:a & kisters-ça \\
\hline 1 s.li -isik. & 295: & 0,5 & refalat \\
\hline Senntl: & 2,816 & 0.5 & fal ibt: \\
\hline serangyqua & 2.868 & 0,5 & ralates \\
\hline Auica & 2957 & 0,5 & retal:s: \\
\hline Etroll & 3861 & 0.5 & ralabe: \\
\hline she: $|k i|$ & Ilysil & Min be is: & imstrenyan \\
\hline 4kses & $0: 43$ & 6 & refata: \\
\hline 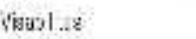 & $0,5 / 8$ & ces & Ielatos \\
\hline a. Intas & $0,5^{\circ} ;$ & $c$ & relabal \\
\hline TEmpanprat & 0,524 & ce & relobst \\
\hline $\begin{array}{l}\text { Sele:akicas rodk } \\
x^{2}\end{array}$ & Hasi & Bloikt:rs & Betesonon \\
\hline Seropumar & 3354 & 36 & relsabel \\
\hline Antersotasn & a93! & 2,6 & relats: \\
\hline vaten idact: & 0,055 & 36 & relabul \\
\hline $\begin{array}{l}\text { Sequbusan Pembelinn } \\
y\end{array}$ & Hosi & klolktis & Peteranoa \\
\hline A:sranlasen 'Skntuli & anse & 3.6 & relatis: \\
\hline "entresongen dolear & 9651 & 26 & relinbel \\
\hline $\begin{array}{l}\text { ¿soeade ar bebutuown } \\
\text { Jonkengnan }\end{array}$ & 993 & 36 & relisbel \\
\hline
\end{tabular}

Dijelaskan uji reliabilitas masingmasing indikator lebih besar dari 0,6 maka dapat disimpulkan pernyataan dalam penelitian ini reliabel/konsisten.

Tabel 3.

Hasil Uji Normalitas 
Hasi uj Hornaltes

\begin{tabular}{|c|c|c|}
\hline & & 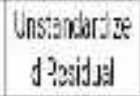 \\
\hline \multicolumn{2}{|l|}{ i } & 151 \\
\hline \multirow[t]{2}{*}{ WumalParante:s" } & He: & .600000 \\
\hline & Sic. Revialigu & 639134989 \\
\hline \multirow[t]{3}{*}{ 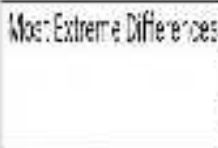 } & I.s80.te & .550 \\
\hline & Fosnite & 90 \\
\hline & Heyghive & .160 \\
\hline \multicolumn{2}{|l|}{ Tetstistic } & $.5,89$ \\
\hline \multicolumn{2}{|l|}{ 4smp. 3t htiks } & $33^{6}$ \\
\hline
\end{tabular}

Dijelaskan uji normalitas sebesar 0,063>0,05 maka dapat diartikan data dalam penelitian ini berdistribusi normal.

Tabel 4.

Hasil Uji Multikolineritas

\begin{tabular}{|c|c|c|}
\hline \multirow[b]{2}{*}{ Navel } & \multicolumn{2}{|c|}{ Collnority Staistcs } \\
\hline & \multirow[t]{2}{*}{ Tolemeres } & \multirow[t]{2}{*}{$y F$} \\
\hline (Bonstart) & & \\
\hline Kualizas lạa an & .81 & 1041 \\
\hline Lteks| & 60 & 1011 \\
\hline Kelergkanar procke & 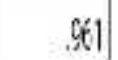 & 1041 \\
\hline
\end{tabular}

Dijelaskan penelitian ini tidak terjadi kesamaan antar variabel bebas, tidak sesuai dengan nilai Tolerance yang > 0,10 dan nilai VIF yang $<10$.
Tabel 6.

Uji Autokorelasi

\begin{tabular}{c|c}
\hline Model & $\begin{array}{c}\text { Durbin- } \\
\text { Watson }\end{array}$ \\
\hline 1 & 1.767 \\
\hline
\end{tabular}

Dijelaskan perhitungan nilai $\mathrm{dw}$ sebesar 1,767 berada diantara 1,5-2,5 maka dapat disimpulkan tidak terjadi autokorelasi dalam data penelitian ini.

Tabel 5.

Uji Heteroskedastisitas

Tabel 7. 
Analisis Regresi Linier Berganda

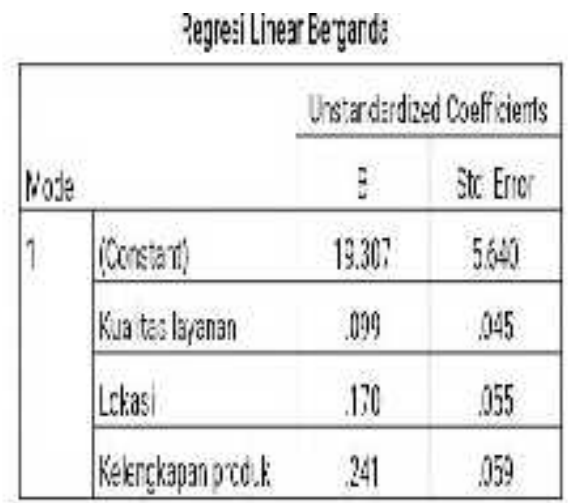

Dari persamaan tersebut, dapat dijelaskan sebagai berikut:

1. Nilai konstanta sebesar 19,307

Dijelaskan Koefisien regresi pada konstanta sebesar 19,307. apabila Kualitas Layanan, Lokasi, dan Kelengkapan produk nilainya 0, maka Keputusan Pembelian meningkat sebesar 19,307.

2. Dijelaskan koefisien variabel kualitas layanan sebesar .099. bahwa setiap kenaikan satu satuan Kualitas Layanan akan mengakibatkan meningkatnya Keputusan Pembelian sebesar ,099.

3. Dijelaskan koefisien variabel Lokasi sebesar ,170. bahwa setiap kenaikan atau penambahan satu satuan Lokasi akan mengakibatkan meningkatnya Keputusan Pembelian sebesar ,170.

4. Dijelaskan koefisien variabel Kelengkapan produk sebesar ,241 bahwa setiap kenaikan atau penambahan satu satuan Kelengkapan produk akan mengakibatkan meningkatnya Keputusan Pembelian sebesar ,241. Tabel 8. Uji-t

\begin{tabular}{|c|c|c|c|}
\hline \multicolumn{4}{|c|}{ Hasilujit } \\
\hline \multicolumn{2}{|c|}{ Modal } & 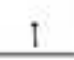 & Sig \\
\hline \multirow[t]{4}{*}{1} & (Constant); & 3.423 & 001 \\
\hline & Kualitas layarian & 2.189 & 030 \\
\hline & Lokasi & 3.107 & 002 \\
\hline & $\begin{array}{l}\text { Ke engkapan } \\
\text { duk }\end{array}$ & 4.104 & 500 \\
\hline
\end{tabular}

Dijelaskan hasil pengujian parsial penjelasan uji t:

1. Variabel Kualitas layanan, nilai signifikansi $.030<, 05$. variabel Kualitas layanan berpengaruh positif dan signifikan terhadap Keputusan Pembelian.

2. Variabel Lokasi, nilai signifikansi $.002<, 05$. variabel Lokasi berpengaruh terhadap Keputusan Pembelian.

3. Variabel kelengkapan produk diketahui nilai signifikansi $0,000<$ 0,05 variabel kelengkapan produk berpengaruh positif dan signifikan terhadap Keputusan Pembelian.

\section{Tabel 9}

Uji-f

\begin{tabular}{|c|c|c|c|}
\hline \multicolumn{4}{|c|}{ Hasil Uji F } \\
\hline \multicolumn{2}{|c|}{ Modal } & $F$ & Sig. \\
\hline \multirow[t]{3}{*}{1} & Regression & 12.156 & $.000^{b}$ \\
\hline & Residual & & \\
\hline & Total & & \\
\hline
\end{tabular}

Dijelaskan nilai $\mathrm{F}$ hitung $=12,156$ serta ,000 <,05, maka HO di tolak 
yang artinya Kualitas Layanan, Lokasi, dan Kelengkapan produk berpengaruh secara simultan terhadap Keputusan Pembelian.

\section{SIMPULAN}

Dijelaskan hasil penelitian dapat disimpulkan, pada analisis pengaruh kualitas layanan terhadap Keputusan Pembelian Apotek Kencana Mas terbukti berpengaruh positif terhadap Keputusan Pembelian Apotek Kencana Mas.

$$
\text { Analisis pengaruh lokasi }
$$
terhadap Keputusan Pembelian Apotek Kencana Mas terbukti berpengaruh positif terhadap Keputusan Pembelian Apotek Kencana Mas.

Analisis pengaruh Kelengkapan produk terhadap Keputusan Pembelian Apotek Kencana Mas terbukti berpengaruh positif dan signifikan terhadap Keputusan Pembelian Apotek Kencana Mas.

Analisis pengaruh Kualitas Layanan, Lokasi, dan Kelengkapan produk berpengaruh simultan terhadap Keputusan Pembelian terbukti berpengaruh terhadap keputusan pembelian Apotek Kencana Mas.

\section{IMPLIKASI}

1. Kualitas Layanan sangat mempengaruhi konsumen untuk melakukan keputusan pembelian produk obat-obatan di Apotek kencana mas, sehingga peningkatan kualitas layanan akan memberikan dampak yang baik bagi penjualan Apotek kencana mas.

\section{KETERBATASAN PENELITIAN}

Pada penelitian ini, hanya berfokus pada penelusuran tentang kualitas layanan, lokasi dan Kelengkapan produk yang dapat mengakibatkan munculnya keputusan pembelian produk di kalangan responden. Tidak hanya itu saja, diharapkan penelitian selanjutnya bisa memakai variabel lain untuk melalukan penelitian tentang keputusan pembelian, penelitian ini juga dijadikan bahan pembanding untuk penelitian-penelitian terbaru.

\section{DAFTAR RUJUKAN}

Kotler, Philip. 2012. Manajemen Pemasaran. Edisi ke-13, Jilid 1. Terjemahan: Bob Sabran. Jakarta: Erlangga.

Rachman. 2017. Aplikasi komputer statistik. Adi buana univercsity, Surabaya

Schiffman, L.danKanuk, L.L. 2008 PerilakuKonsumen. Edisi 7. Indeks, Jakarta

Sugiyono.2016.MetodePenelitianBisnis. Bandung: Alfabeta 